\title{
The Pickett equation analytical continuation
}

\author{
Valdemar V. Kutarov • Erich Robens
}

Received: 4 April 2009 / Accepted: 27 September 2011 / Published online: 19 October 2011

(C) The Author(s) 2011. This article is published with open access at Springerlink.com

\begin{abstract}
Usually gas adsorption isotherms are evaluated by means of the classic two-parameter equation of Brunauer, Emmett and Teller (BET II). This equation however fails when multilayer adsorption or capillary condensation occurs. The present work suggests the use of the threeparameter Pickett equation in the range of high adsorptive pressure of the gaseous phase. An analytical continuation of the Pickett equation allows for the description of the whole isotherm. Adsorption isotherms of krypton, water vapor, and $n$-heptane at Lunar regolith samples are evaluated using both, BET II and continued Pickett equation.
\end{abstract}

Keywords Adsorption - BET-equation · Moon ·

Pickett-equation $\cdot$ Regolith $\cdot$ Surface

\section{Introduction}

Most statistical theories of multi-layer adsorption, used presently for the analysis of experimental data, are based on the latticed gas model (Hill 1972; Brunauer et al. 1966/1967). In practice most evaluations of gas adsorption are made by means of the theory of Brunauer, Emmett, Teller (BET) (Brunauer et al. 1938), or use of modified BET equations as suggested e.g. by Aranovich (1993), Tovbin

V.V. Kutarov ( $\varangle)$

Physical Research Institute, I.I. Mechnikov Odessa National University, 27 Pastera St., Odessa 65082, Ukraine

e-mail: v.kutarov@onu.edu.ua

\section{E. Robens}

Institut für Anorganische Chemie und Analytische Chemie,

Johannes Gutenberg-Universität, Duesbergweg 10-14,

55099 Mainz, Germany

e-mail: erich.robens@t-online.de
(1993), and Shkilev (2002). In addition many numerical methods exist basing on the lattice model for the analysis of experimental multi-layer adsorption isotherms (Mamleev et al. 1992; Tarasevich and Aksenenko 2005). The present paper concerns a modified BET equation: the Pickett equation (Pickett 1958) and its further development.

\section{The Pickett equation}

Whereas the classical BET equations includes two characteristic parameters, modifications proposed in particular by Aranovich (1993), Tovbin (1993), Shkilev (2002), contain usually three or four adjusting parameters (Keller and Staudt 2004). Though some of those parameters have a clear thermodynamic signification their determination on experimental isotherms is not always possible. Besides, most presently known modifications of the BET equations by introduction of more parameters describe isotherm well only in the area of multi-layer saturation (Kats et al. 1991; Kats and Kutarov 1998).

The present work suggests an analytical extension of the classical BET equation-the Pickett (1958) equation-in the range of high adsorptive pressure of the gaseous phase. In its classic form BET equation may be written as follows (Kats et al. 1991):

$a=a_{m} \frac{C \sum_{i=0}^{\infty} i x^{i}}{1+C \sum_{i=0}^{\infty} x^{i}}$

where $a_{m}$ is the monolayer capacity; $x$ the relative adsorptive pressure in the gaseous phase (see Table 1); and

$$
C=\frac{x}{y} ; \quad y=\frac{\alpha_{1}}{\beta_{1}} \exp \left(\frac{E_{1}}{R T}\right) ; \quad x=\frac{P}{g} \exp \left(\frac{E_{L}}{R T}\right)
$$


Table 1 List of symbols

\begin{tabular}{|c|c|c|c|}
\hline Symbol & Signification & Definition & SI unit \\
\hline$a$ & Adsorbed amount & & mol \\
\hline$a_{m}$ & Monolayer capacity & & mol \\
\hline$C$ & BET number & $C=\frac{\alpha_{1} g}{\beta_{1}} \exp \frac{\left(E_{1}-E_{L}\right)}{R T}$ & \\
\hline$E_{1}$ & Adsorption heat of the $i$ th layer & & \\
\hline$E_{L}$ & Liquefaction heat & & \\
\hline$\beta_{i} ; \alpha_{i}$ & Parameters of BET theory & & \\
\hline$g$ & & $g=\frac{\beta_{i}}{\alpha_{i}}$ & \\
\hline$i$ & Running index & $i=0 \ldots n$ & \\
\hline$k$ & Running index & & \\
\hline$q$ & Exponent & & \\
\hline$m_{a}$ & Adsorbed mass per unit sample mass & & $\mathrm{g}$ \\
\hline$n$ & Number of layers & & \\
\hline$p$ & Gas pressure & & $\mathrm{Pa}$ \\
\hline$p_{s}$ & Saturation gas pressure & & $\mathrm{Pa}$ \\
\hline$R$ & Universal gas constant & 8.314 & $\mathrm{~J} \mathrm{~mol}^{-1} \mathrm{~K}^{-1}$ \\
\hline$T$ & Absolute temperature & & $\mathrm{K}$ \\
\hline$V_{a}$ & Adsorbed gas volume per unit sample mass & & $\mathrm{cm}^{3} \mathrm{~g}^{-1}$ \\
\hline$x$ & $\begin{array}{l}\text { Relative pressure }=\text { adsorptive pressure } \\
\text { in the gaseous phase to saturation pressure }\end{array}$ & $x=\frac{p}{p_{s}}$ & \\
\hline
\end{tabular}

It is usually accepted that

$$
\begin{aligned}
& E_{2}=E_{3}=\cdots=E_{i}=E_{L} \\
& \frac{\beta_{2}}{\alpha_{2}}=\frac{\beta_{3}}{\alpha_{3}}=\cdots=\frac{\beta_{i}}{\alpha_{i}}=g
\end{aligned}
$$

The correctness of terms (2) was often criticized. In particular the condition of the two-parameter BET equation (1) of the possible formation of an infinite number of adsorbed layers contradicts reality. Indeed in porous and finely divided matter the layer formation is limited in general by opposite walls. Thus, the assumption of the formation of a finite number of layers $n$ on the adsorbing surface seems to be more realistic. Basing on this assumption and summing up the layers just to $n$ Brunauer, Demming, Demming and Teller got a three-parameter equation for multi-layer adsorption isotherms (Kats et al. 1991; Brunauer et al. 1940):

$a=a_{m} \frac{C x}{1-x} \frac{1-(n+1) x^{n}+n x^{n+1}}{1+(C-1) x-C x^{n+1}}$

The parameters $a_{m}$ and $C$ in (3) correspond to that in (1). For $n=1$ (3) changes into the Langmuir equation, and for $n=2$ into the Hüttig equation (Kats et al. 1991; Hüttig 1948). Disadvantageously it is not possible to calculate from (3) the value of the adsorbed amount at $p \rightarrow p_{s}$ because its application at $n>2$ provides considerable difficulties. Therefore Pickett introduced a variation of the two- parameter BET equation. He supposed, that for the last layer value $b_{i} / a_{i}$ assumption (2) is not equal to $g$, but to $g(1-x)$. Utilizing this assumption and summing up layers from $i=0$ to $i=n$ in (1), Pickett obtained the three-parameter equation (Kats et al. 1991):

$a=a_{m} \frac{C x\left(1-x^{n}\right)}{(1-x)(1-x+C x)}$

In general case, that (4) is valid for the value $x_{p} \approx 0.8$ and describes the adsorption isotherm only in the area of multilayer film formation. Indeed, depending on the concrete adsorption system isotherms are described well in the interval (0.5-0.97) (Kats et al. 1991; Kats and Kutarov 1998).

\section{Continuation of the Pickett equation}

Let's see how it is possible to describe in the frames of (4) formalism the complete isotherm in the monolayer and multilayer region, taking into account the assumptions given by Pickett and Dellyes (Dellyes 1963). On the basis of numerous experimental data analysis (Kats et al. 1991; Kats and Kutarov 1998), and also taking into account ZimmLandsberg and Flori-Huggins theories (Zimm and Lundberg 1956; Huggins 1971), it is possible to suppose that on the right hand side of (4) of multi-layer saturation point the speed of local equilibrium constant value diminishing will be slowed down, as compared to the corresponding value of 


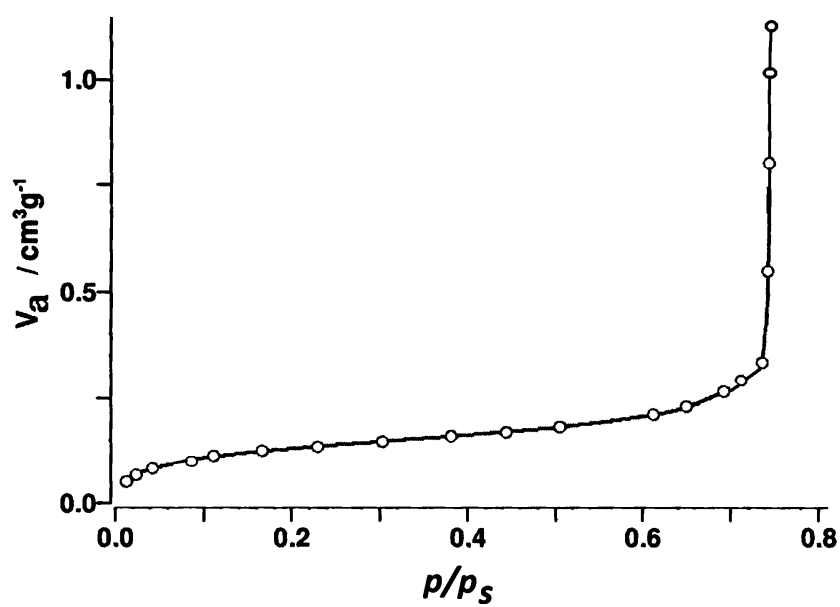

Fig. 1 Krypton adsorption isotherm at 77.1 K of lunar regolith sample 10084.2000. The ordinate represents the adsorbed gas volume at S.T.P. divided by the mass of the degassed sample $\left[\mathrm{cm}^{3} \mathrm{~g}^{-1}\right]$. The abscissa is the measured pressure above the capillary of the sample vessel related to the saturation pressure of $233 \mathrm{~Pa}$. \#UL1511 OPOROTEC

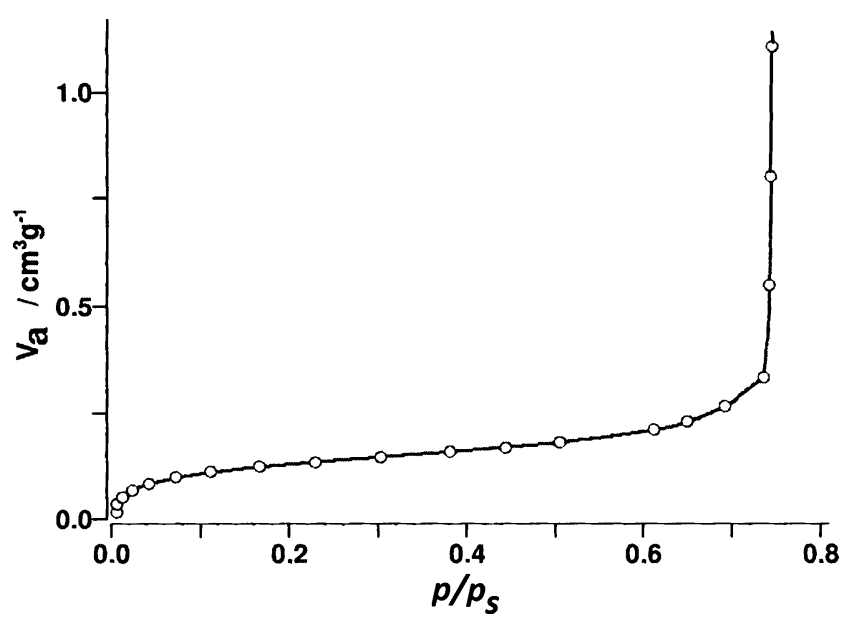

Fig. 2 Krypton adsorption isotherm at $77.1 \mathrm{~K}$ of lunar regolith sample 12001.922. The ordinate represents the adsorbed gas volume at S.T.P. divided by the mass of the degassed sample $\left[\mathrm{cm}^{3} \mathrm{~g}^{-1}\right]$. The abscissa is the measured pressure above the capillary of the sample vessel related to the saturation pressure of $233 \mathrm{~Pa}$. \#UL1564 CPOROTEC

multi-layer saturation point on the left; and this deceleration can be presented as a degree function from the value of $x$, with exponent $q$. In this case it is necessary to write down (1) in the form

$$
a=a_{m} \frac{C\left[\sum_{i=1}^{n-1} i x^{i}+\frac{n x^{n}}{1-x}+\frac{x^{q}}{1-x} \sum_{i=n+1}^{\infty} i x^{i}\right]}{1+C \sum_{i=1}^{\infty} x^{i}}
$$

In (5) the second term in square brackets determines the Pickett amendment and the third term is introduced for description of the isotherm part above the multi-layer saturation point. For large values of the adsorption system $(C>$

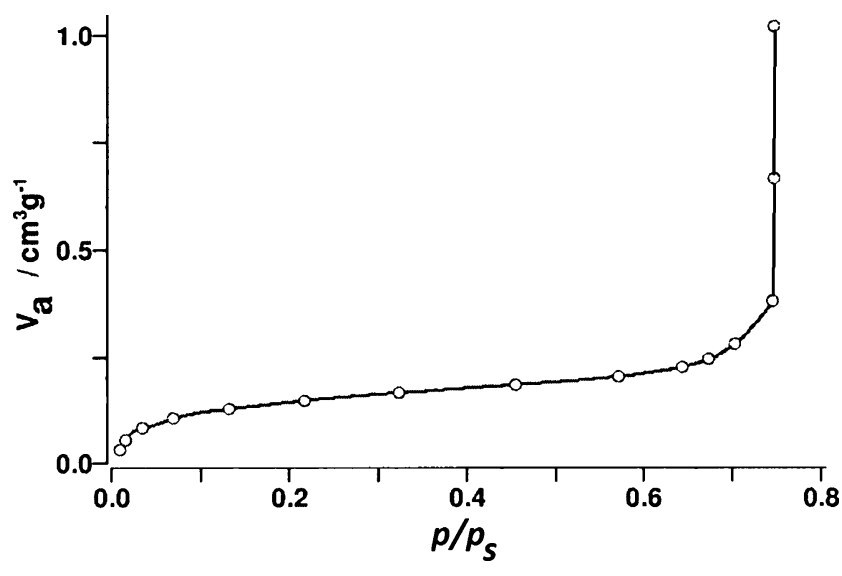

Fig. 3 Krypton adsorption isotherm of lunar regolith sample 64501.228. \#UL1565 CPOROTEC

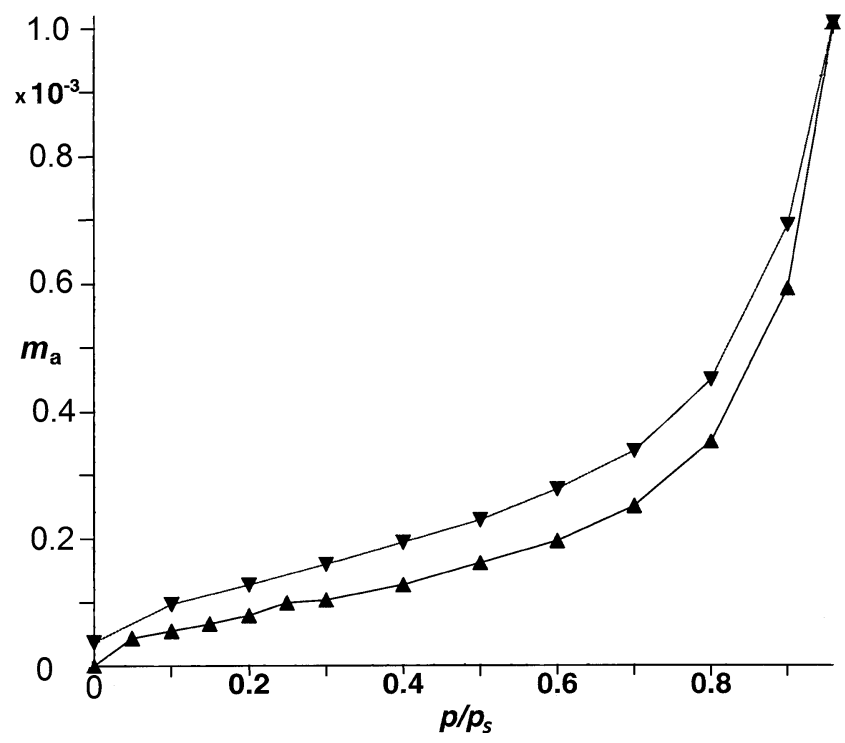

Fig. 4 Water adsorption and desorption isotherm at $24.9^{\circ} \mathrm{C}$ of lunar regolith sample 12001.922. ( $\mathbf{\Delta}$ ) adsorption, $(\boldsymbol{\nabla})$ desorption, $m_{a}$ adsorbed water mass related to sample mass, $p / p_{0}$ water vapor pressure related to saturation pressure (relative humidity). \#UL1843a.jpg. CPOROTEC

50) summing up in (5) results in the following equation:

$a=a_{m} \frac{x C\left[(1-x)\left(1-x^{n}\right)+x^{n+q}\right]}{(1-x)^{2}[1+x(C-1)]}$

Infinite summing up in (5) agrees with the experimental isotherms in the sense, that for isotherms with $C>50$ the line of $x=1$ can be considered as vertical asymptotic. The adsorption isotherm equation (6) at $x \rightarrow 1$ presents the infinite value of filling, which is caused by such an accepted infinite summing up.

For isotherms characterized by small receptivity value $(C<50)$ the isotherm at $x \rightarrow 1$ practically crosses the line of $x=1$. In this case the summing up of the last row in of 
Table 2 Adsorption data. $a_{m}$ are given in $\mathrm{mmol} \mathrm{g}^{-1}$

\begin{tabular}{llllllllll}
\hline Sample & Ads. & $\begin{array}{l}a_{m} \\
\text { BET }\end{array}$ & $\begin{array}{l}a_{m} \\
\text { EP }\end{array}$ & $\begin{array}{l}C \\
\text { BET }\end{array}$ & $\begin{array}{l}C \\
\text { EP }\end{array}$ & $n$ & $q$ & BET region & EP region \\
\hline 10084 & $\mathrm{Kr}$ & 0.11 & 0.114 & 29.2 & 29.2 & 2.1 & 8.1 & $0.05 \leq x<0.4$ & $0.05 \leq x \leq 0.85$ \\
12001 & $\mathrm{Kr}$ & 0.11 & 0.111 & 61.7 & 61.75 & 3.1 & 7.0 & $0.007 \leq x<0.44$ & $0.007 \leq x<0.74$ \\
64501 & $\mathrm{Kr}$ & 0.14 & 0.139 & 82.2 & 82.2 & 2.15 & 6.28 & $0.02 \leq x<0.4$ & $0.02 \leq x<0.74$ \\
12001 & $\mathrm{H}_{2} \mathrm{O}$ & 0.09 & 0.087 & 12.7 & 12.7 & 9.9 & 47.1 & $0.05 \leq x<0.6$ & $0.05 \leq x<1.0$ \\
64501 & $\mathrm{H}_{2} \mathrm{O}$ & 0.01 & 0.0091 & 54.8 & 54.8 & 4.8 & 32 & $0.05 \leq x<0.6$ & $0.05 \leq x<0.9$ \\
12001 & $\mathrm{C}_{7} \mathrm{H}_{16}$ & 0.01 & 0.011 & 147 & 147 & 3.3 & 32.7 & $0.05 \leq x<0.4$ & $0.05 \leq x<0.95$ \\
\hline
\end{tabular}

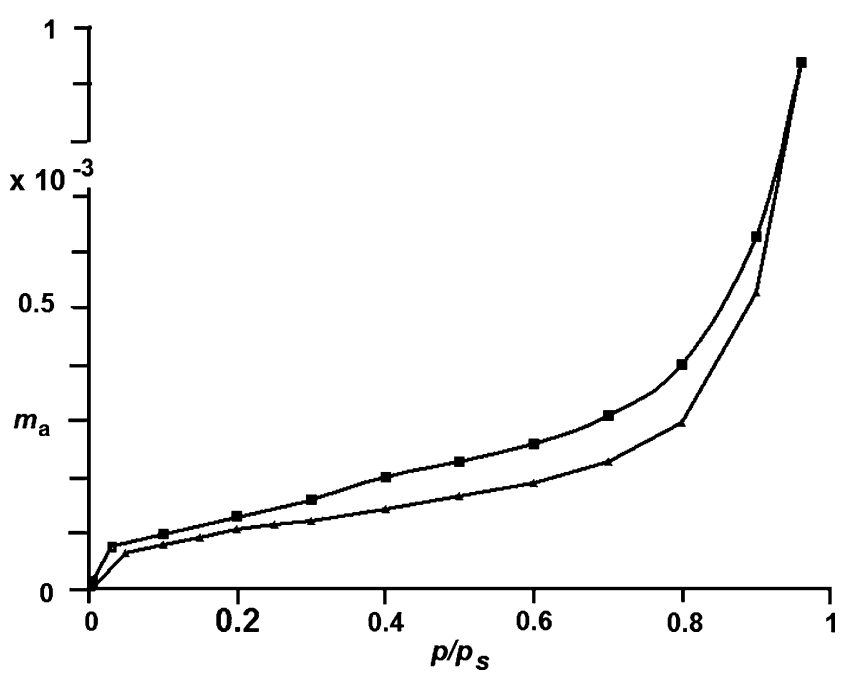

Fig. 5 Water adsorption isotherm at $24.9^{\circ} \mathrm{C}$ of lunar regolith sample 64501.228 \#UL1842.jpg @POROTEC

(5) numerator should be continued to some finite value $k$ :

$a=a_{m} \frac{C\left[\sum_{i=1}^{n-1} i x^{i}+\frac{n x^{n}}{1-x}+\frac{x^{q}}{1-x} \sum_{i=n+1}^{k} i x^{i}\right]}{1+C \sum_{i=1}^{\infty} x^{i}}$

Summing up in (7) results in following equation

$$
\begin{aligned}
a= & a_{m} \frac{C x\left(1-x^{n}\right)}{(1-x)[1+x(C-1)]} \\
& \times\left\{1+x^{n+q}\left[(n+1)\left(1-x^{n}\right)-k x^{k}\right]\right\}
\end{aligned}
$$

It is easy to see that at all reasonable values at $k>n$ the value $k x^{k}$ at $x>x_{p}$ has a magnitude at level 0.05 and in the first approximation its value can be possibly ignored. Then the final equation of adsorption will be written down in the form

$a=a_{m} \frac{C x\left(1-x^{n}\right)}{(1-x)[1+x(-1)]}\left[1+(n+1)\left(1-x^{n}\right) x^{q+n}\right]$

Equation (9) at $x \rightarrow 1$ gives the finite value of filling:

$a=a_{m}\left[\frac{n(2 C-1)+(C-1)}{C}\right]$

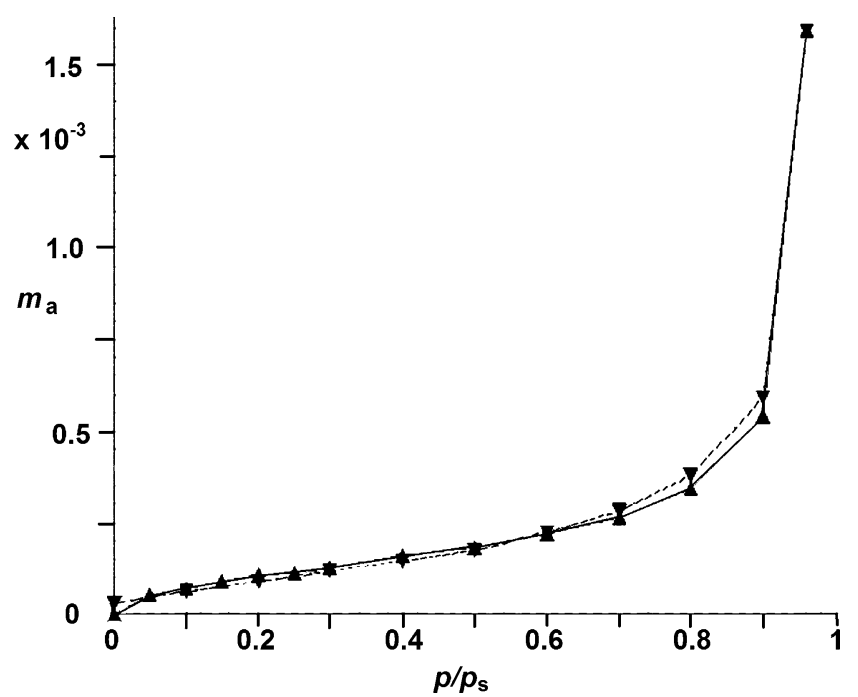

Fig. $6 n$-Heptane $\mathrm{C}_{7} \mathrm{H}_{16}$ adsorption and desorption isotherm at $24.9^{\circ} \mathrm{C}$ of lunar regolith sample 12001.922. ( $\left.\mathbf{\Delta}\right)$ adsorption, $(\boldsymbol{\nabla})$ desorption. $m_{a}$ adsorbed heptane mass related to sample mass, $p / p_{0}$ heptane pressure related to saturation pressure. \#UL1895.jpg CPOROTEC

\section{Evaluation of adsorption measurements}

Some adsorption measurements of various gases at lunar regolith fine-grained sand $(\varnothing<100 \mu \mathrm{m})$ published elsewhere (Robens et al. 2007, 2008) were evaluated using the BET II equation (1) and the Expanded Pickett equation (EP) (6) or (9). The evaluated isotherms are shown in Figs. 1-6. The results are compared in Table 2.

\section{Discussion}

The two-parameter equation of Brunauer, Emmett, and Teller (BET II) is standard for evaluation of gas adsorption isotherms in the monolayer region. The three-parameter Pickett equation take into account limitations of multilayer expansion due to the porous structure of the solid sample and describes isotherms well in the multilayer region. Expansion of the Pickett equation allows for the description of the complete isotherm. 
Evaluation of Adsorption isotherms of krypton, water vapor, and $n$-heptane at Lunar regolith samples, demonstrate the correct description of the isotherm in nearly its whole range by the expanded Pickett equation. As expected the values of the specific surface area and of the $C$-value are not affected and equal to those obtained by BET II (Figs. 1-6).

Acknowledgements We are obliged to Dr. Andreas Schreiber, POROTEC GmbH, Hofheim, Germany for the measurements of the adsorption isotherms.

Open Access This article is distributed under the terms of the Creative Commons Attribution Noncommercial License which permits any noncommercial use, distribution, and reproduction in any medium, provided the original author(s) and source are credited.

\section{References}

Hill, T.L.: Statistical Mechanics. Mir, Moscow (1972)

Brunauer, S., Copeland, L., Kantro, D.: Theory of Langmuir and Brunauer, Emmett and Teller. In: Flood, E.A. (ed.) The Solid-Gas Interface, p. 77. Dekker, New York (1966/1967)

Brunauer, S., Emmett, P.H., Teller, E.: Adsorption of gases in multimolecular layers. J. Am. Chem. Soc. 60(2), 309-319 (1938)

Aranovich, G.L.: Russ. J. Phys. Chem. 67(11), 2323-2324 (1993)
Tovbin, Y.K.: Russ. J. Phys. Chem. 67(11), 2325-2327 (1993)

Shkilev, V.P.: Russ. J. Phys. Chem. 76(2), 325-330 (2002)

Mamleev, B.H., Astapenkova, L.V., Gladyshev, P.P.: Russ. J. Phys. Chem. 66(8), 2148-2174 (1992)

Tarasevich, Y.I., Aksenenko, E.V.: Russ. J. Theor. Exp. Chem. 41(5), 283-289 (2005)

Pickett, G.: J. Am. Chem. Soc. 67, 1958 (1958)

Keller, J.U., Staudt, R.: Gas Adsorption Equilibria. Experimental Methods and Adsorptive Isotherms. Springer, Heidelberg (2004)

Kats, B.M., Kutovaya, L.M., Kutarov, V.V.: Kinetics of adsorption of water vapor by anion-exchange fibers on the basis of cellulose and polyacrylonitrile. J. Appl. Chem. 64(8), 1713-1716 (1991)

Kats, B.M., Kutarov, V.V.: A modified BET equation for polylayer adsorption. Adsorp. Sci. Technol. 16(4), 257-262 (1998)

Brunauer, S., et al.: On a theory of the van der Waals adsorption of gases. J. Am. Chem. Soc. 62(7), 1723-1732 (1940)

Hüttig, G.F.: Zur Auswertung der Adsorptions-Isothermen. Monatsh. Chem. 78(3-4), 177-184 (1948)

Dellyes, R.: Modification a la Theorie BET et nouvelles possibilites d'application. J. Chim. Phys. 60, 1008-1016 (1963)

Zimm, B.H., Lundberg, J.L.: Sorption of vapors by high polymers. J. Phys. Chem. 60(4), 425-428 (1956)

Huggins, H.G.: J. Phys. Chem. 75, 1265 (1971)

Robens, E., et al.: Investigation of surface properties of lunar regolith. Part I. Appl. Surf. Sci. 253, 5709-5714 (2007)

Robens, E., et al.: Investigation of surface properties of lunar regolith. Part II. J. Therm. Anal. Calorim. 94(3), 627-631 (2008) 